\title{
PENGARUH INTRAPRENEURSHIP TERHADAP KINERJA PERUSAHAAN MANUFAKTUR DI TANGERANG
}

\author{
Rita Friana dan Ina Indriana \\ Fakultas Ekonomi Universitas Sultan Ageng Tirtayasa \\ Email: rita.friana@yahoo.com
}

\begin{abstract}
This study aims to investigate the influence of intrapreneurship on the performance of manufacturing companies in Tangerang. The population was manager of a manufacturing company in the province of Banten. This study developed and tested a theoretical model where the variable intrapreneurship shaped by factors of innovation, risk / uncertainty, risks / challenges, competitive energy, proactive and autonomy, and performance on financial performance variables, variables and variable productivity growth and repair. Based on the questionnaire, which is selected using purposive sampling method of data obtained from a sample of 25 medium-sized companies manufacturing in Tangerang. This study uses confirmatory analysis based on structural equation modeling (SEM). This research model using AMOS 21.0. The results of this study revealed that intrapreneurship has a multidimensional structure. Innovation factors, risks / challenges, competitive and proactive energy can explain well intrapreneurship. This model proved its effect on the growth and repair. Intrapreneurship affect the growth and repair. This study contributes to theory highlights the importance of intrapreneurship-forming factors and their effects in the model. This is helpful for researchers looking for appropriate performance measures and intrapreneurs aims to support their decisions and evaluate their performance.
\end{abstract}

Keywords: intrapreneurship, innovation, risk / challenge, competitive energy, proactive, growth and repair

\begin{abstract}
Abstrak: Penelitian ini bertujuan untuk meneliti pengaruh intrapreneurship terhadap kinerja perusahaan manufaktur di Tangerang. Populasi penelitian ini adalah manajer perusahan manufaktur di Provinsi Banten. Penelitian ini mengembangkan dan menguji sebuah model teoritis dimana variabel intrapreneurship dibentuk oleh faktor inovasi, risiko / ketidakpastian, resiko / tantangan, energi kompetitif, proaktif dan otonomi, dan kinerja pada variabel kinerja keuangan, variabel produktivitas serta variabel pertumbuhan dan perbaikan. Berdasarkan kuesioner, yang dipilih menggunakan metode purposive sampling diperoleh data dari sampel 25 perusahaan menengah manufaktur di Tangerang. Penelitian ini menggunakan metode analisis konfirmasi yang didasarkan pada model persamaan struktural (SEM). Model penelitian ini menggunakan AMOS 21.0. Hasil dari penelitian ini mengungkapkan bahwa intrapreneurship memiliki struktur multidimensi. Faktor inovasi, risiko / tantangan, energi kompetitif dan proaktif dapat menjelaskan intrapreneurship dengan baik. Model ini membuktikan pengaruhnya pada pertumbuhan dan perbaikan. Intrapreneurship berpengaruh terhadap pertumbuhan dan perbaikan. Penelitian ini memberikan kontribusi untuk menyoroti teori pentingnya faktor pembentuk intrapreneurship dan pengaruhnya dalam model. Hal ini bermanfaat bagi para peneliti mencari ukuran kinerja yang tepat dan intrapreneur bertujuan untuk mendukung keputusan mereka serta mengevaluasi kinerja mereka.
\end{abstract}


Kata kunci: intrapreneurship, inovasi, risiko/tantangan, energi kompetitif, proaktif, pertumbuhan dan perbaikan

\section{PENDAHULUAN}

Meningkatkan kinerja dalam sebuah organisasi atau instansi pemerintah merupakan tujuan atau target yang ingin dicapai oleh organisasi dan instansi pemerintah dalam memaksimalkan suatu kegiatan yang telah di tetapkan sebelumnya.Lingkungan bisnis saat ini mulai bergerak dari yang bersifat lokal ke global, dan hanya yang terkuat yang dapat bertahan hidup untuk memiliki kinerja organisasi yang baik. Pengelolaan bisnis harus mampu menciptakan keunggulan kompetitif, tidak hanya itu tetapi juga sulit untuk ditiru. Selain itu, perusahaan harus memiliki sikap proaktif terhadap kondisi ketidakpastian dalam menghadapi tantangan global yang ada. Inovasi dalam persaingan atau strategi, semakin global, menciptakan bidang penelitian dan kompleksitas dunia baru yang berpeluang mengarahkan perusahaan dapat berkelanjutan dalam jangka panjang. Intrapreneurship adalah sebuah strategi untuk menstimulasi inovasi dengan memanfaatkan bakat-bakat kewirausahaan dengan lebih baik. Ketika intrapreneurship ini di dorong dan disalurkan, intrapreneurship bukan hanya mendorong inovasi,bahkan akan membantu pegawai yang mempunyai ide-ide bagus menyalurkan sumber daya perusahaan untuk membangun produk-produk yang lebih unggul. Dengan mendorong budaya intrapreneur dalam perusahaan, pegawai dapat diberdayakan menjadi agen perubahan dalam perusahaan. Mereka merasa nyaman menampilkan ide-ide baru dan merasa diberikan otonomi dan mendorong agar ide-ide tersebut dilaksanakan. Sehingga dengan penerapan intrapreneurship dalam suatu perusahaan dapat meningkatkan kinerja perusahaan, terutama kinerja keuangan perusahaan (Betti alisjahbana, 2012).

Menurut Wirawan (2012) dampak dari peran intrapreneur sendiri sangat positif bagi pihak internal maupun eksternal perusahaan.Yang lebih menarik lagi adalah kemampuan intrapreneur untuk meningkatkan "cooperative advantage" dari perusahaan dimana mereka berada sehingga perusahaan mampu bersaing dalam banyak hal.

Menurut Hisrich (2005) Intrapreneurship merupakan kewirausahaan yang ada di dalam struktur bisnis yang ada, yang dapat menjembatani kesenjangan antara ilmu pengetahuan dan pasar. Bisnis yang ada telah memiliki sumber daya keuangan, kemampuan usaha dan sistem pemasaran dan distribusi untuk memasarkan inovasi yang ada dengan sukses. Namun terkadang struktur perusahaan yang terlalu birokratis, penekanan pada profit jangka pendek dan rumitnya struktur organisasi dapat mengahambat kreatifitas dan pengembangan produk atau usaha.

Unsur kunci dari intrapreneurship di perusahaan besar yang mapan adalah kemampuan kepemimpinan yang kuat bersama budaya integritas, untuk mendukung kecepatan dari setiap proses pengambilan keputusan. Termasuk, kesiapan menciptakan jiwa-jiwa kewirausahaan di dalam perusahaan dari setiap karyawan strategis untuk berkembang bersama kebebasan inovasi dan kreatifitas dalam bingkai transparansi, akuntabilitas, integritas, etika, dan pengendalian emosional diri.

Sekarang ini semua perusahaan besar memimpikan untuk memiliki para karyawan atau manajer yang berjiwa intrapreneurship di dalam perusahaan. Persoalannya, pelaksanaan konsep intrapreneurship di perusahaan besar milik publik atau pemerintah, memerlukan trust dan kredibilitas dari para manajer, untuk menjalankan budaya integritas dengan tulus dan ikhlas sebelum diberikan kepercayaan untuk menjadi intrapreneur. 
Sebab, saat seseorang betul-betul menjalankan perannya sebagai intrapreneur di tempat dia bekerja, maka dia akan memiliki mindset sebagai seorang pengusaha, bukan lagi sebagai seorang profesional atau karyawan. Mindset sebagai seorang pengusaha di perusahaan yang sahamnya bukan milik dia pribadi berpotensi menimbulkan konflik kepentingan, yang bila tidak memiliki kekuatan integritas dan etika, maka perusahaan selalu akan dirugikan dari upaya untuk mencari keuntungan kepentingan pribadi atau kelompok. Djajendra, (2013) Dengan demikian untuk mengembangkan intrapreneur disebuah perusahaan,para manajer atau karyawan harus yang memiliki integritas pribadi yang kuat, cara kerja yang etis dan karyawan yang harus mau mengambil resiko untuk mengembangkan ide unik dan pengendalian emosional. Jika tidak, maka penerapan intrapreneurship justru bisa berakibat menurunnya kinerja organisasi.Beberapa penelitian terdahulu menunjukkan hasil yang tidak konsisten. Di Indonesia, penelitian tentang intrapreneurship masih terbatas dan belum banyak dilakukan. Kajian terdahulu telah merumuskan bahwa intrapeneurship berpengaruh terhadap kinerja perusahaan (Felicio et al. 2012). Sampai saat ini belum ada kajian yang membahas tentang pengaruh intrapreneurship terhadap kinerja perusahaan khususnya perusahaan manufaktur.

Berdasarkan uraian di atas, peneliti tertarik untuk melakukan penelitian pengaruh intrapreneurship terhadap kinerja perusahaan pada perusahaan manufaktur di Kota Tangerang. Alasan peneliti memilih perusahaan manufaktur dikarenakan perusahaan manufaktur merupakan perusahaan yang menjual produknya yang dimulai dengan proses produksi yang tidak terputus mulai dari pembelian bahan baku, proses pengolahan bahan hingga menjadi produk yang siap dijual. Inovasi sangat diperlukan agar dapat bersaing dalam persaingan global. Tangerang menjadi daerah yang akan diteliti karena merupakan pusat manufaktur dan industri di Pulau Jawa dan memiliki lebih dari 1000 pabrik. Banyak perusahaan-perusahaan yang berskala internasional yang memiliki pabrik di lokasi ini. Penelitian ini merupakan replikasi dari penelitian Felicio et al. (2012).

\section{KAJIAN TEORI}

Penelitian ini didukung oleh teori kewirausahaan, kewirausahaan adalah sebuah konsep yang sulit untuk diidentifikasi, karena kurangnya kerangka konseptual untuk menjelaskan dan memprediksi fenomena empiris yang utama adalah fitur pembuatan bisnis (Shane dan Venkataraman, 2000 dalam Felicio et al. 2012). Hal ini mengacu pada proses dimana individu, bertindak secara mandiri atau dalam organisasi, mengejar peluang ekonomi (Sharma dan Chrisman, 1999, Shane dan Venkataraman, 2000 dalam Felicio et al. 2012). Kewirausahaan menjadi istilah yang berhubungan dengan individu atau sekelompok individu yang membuat kombinasi baru dalam organisasi mereka (Lumpkin dan Dess, 1996) dan mungkin berhubungan dengan proses kewirausahaan perusahaan atau intrapreneurship (Covin dan Slevin, 1991).

Intrapreneurship mengacu pada proses yang dilakukan di dalam perusahaan, terlepas dari ukuran, mengarah ke proyek-proyek baru atau kegiatan yang inovatif, termasuk pengembangan produk baru, jasa atau aspek lain (Miller, 1983; Antoncic dan Hisrich, 2001). Covin dan Miles (1999) menjelaskan kegiatan intrapreneurship untuk pembaharuan strategis, redefinisi lingkup, peremajaan organisasi dan regenerasi berkelanjutan.Bosma dan Levie (2010) dan Zahra (1995) meyakini bahwa intrapreneurship adalah faktor kunci untuk pengembangan perusahaan yang menurut Soriano dan Martinez (2007). Ireland et al. (2009), dan Alpkan et al. (2010) dipengaruhi oleh banyak faktor internal. 
Intrapreneurship adalah entrepreneurship yang ada didalam perusahaan. Pinchot (1985) mendefinisikan seorang intrapreneur adalah seorang yang memfokuskan pada inovasi dan kreativitas, dan yang mentransformasi suatu mimpi atau gagasan menjadi usaha yang menguntungkan untuk dioperasikannya dalam lingkup lingkungan perusahaan.

Terdapat tiga pilar dalam intrepreneurship yaitu inovasi, pengambilan resiko yang terkalkulasi, dan kreativitas.Inovasi adalah kemampuan untuk melihat segala sesuatu dengan cara yang baru. Pengambilan resiko yang terkalkulasi merupakan kemampuan untuk mengambil kesempatan yang sudah diperhitungkan dan menganggap kegagalan sebagai suatu pengalaman belajar.Kreativitas merupakan kemampuan untuk memperkirakan berbagai kemungkinan di masa depan dan secara proaktif menciptakan apa yang diidamkan.

Dilihat sebelumnya intrapreneurship dapat diklasifikasikan ke dalam empat dimensi: (1) bisnis baru, (2) inovasi, (3) pembaruan diri, dan (4) proaktif.Bisnis baru adalah karakteristik yang paling menonjol dari intrapreneurship karena dapat menghasilkan penciptaan bisnis baru dalam organisasi yang sudah ada (Stopford dan Baden-Fuller 1994 dalam Felicio et al., 2012) dengan mendefinisikan kembali produk perusahaan (atau jasa) (Rule dan Irwin 1988; Zahra 1991) dan /atau pasar baru berkembang (Zahra 1991). Dalam perusahaan besar juga dapat mencakup pembentukan unit lebih formal otonom atau semiotonom atau perusahaan (Schollhammer 1981, 1982 dalam Antocic dan Hisrich 2001 ), internal bertualang (Hisrich dan Peters 1984 dalam Antocic dan Hisrich 2001), perusahaan yang mulai naik (MacMillan et al. 1984), bisnis otonom unit penciptaan (Vesper 1984), dan newstreams (Kanter dan Richardson 1991).

Resource Based View Theory. Penelitian ini juga mengadopsi teori Resource based View $(R B V)$, didukung oleh gagasan bahwa perusahaan-perusahaan yang sukses mempertahankan keunggulan kompetitif memungkinkan akses ke instrumen berkualitas tinggi dan sumber daya yang langka serta sulit ditiru (Grant, 1991; Ray et al. 2004). Menurut Hornsby et al. (2002), intrapreneurship berfokus pada revitalisasi dan memperkuat kompetensi perusahaan untuk memperoleh keterampilan dan kemampuan inovatif, itulah sebabnya peran yang mereka mainkan dalam mencapai keunggulan kompetitif telah mendapatkan imbalan/kompensasi (Long dan Vickers-Koch, 1995 dalam Felicio et al. 2012; McGee dan Finney, 1997 dalam Felicio et al. 2012). Sumber utama dari keuntungan ini terletak pada sumber daya perusahaan, bakat para karyawan dan kemampuan yang diidentifikasi dengan sumber daya berwujud (Grant, 1991; Day, 1994).Oleh karena itu, pandangan berbasis sumber daya (RBV) menganggap intrapreneurship sebagai instrumen dasar untuk konversi, akumulasi dan memanfaatkan sumber daya untuk tujuan kompetitif (Floyd dan Wooldridge, 1999 dalam Felicio et al. 2012).Hasilnya adalah fokus pada pengembangan dan pemanfaatan produk, inovasi administrasi dan peremajaan dan redefinisi perusahaan atau industri (Covin dan Miles, 1999).Kakati (2003) menemukan bahwa sumber daya perusahaan adalah kunci untuk kelangsungan hidup dan pengembangan proyek-proyek baru dan bahwa pengusaha sukses mengembangkan sumber daya berbagai perusahaan untuk mendukung strategi bisnis mereka dan memastikan pengembangan perusahaan. Dalam hal ini, tim dengan kapasitas untuk inisiatif dan inovasi sangat penting dalam proses intrapreneurship (Bruyat dan Julien, 2001; Alpkan et al. 2010). Dalam bidang ini, Wiklund dan Shepherd (2003) menyatakan bahwa perusahaan-perusahaan dengan sumber daya strategis yang lebih mampu bertahan dan berkembang. 
Intrapreneurship merupakan jiwa kewirausahaan dalam perusahaan. Intrapreneurship akan tumbuh jika karyawan perusahaan memiliki semangat untuk melakukan inovasi, berani mengambil resiko (pengambilan resiko yang terkalkulasi), berani menghadapi tantangan, memiliki semangat untuk bersaing, proaktif terhadap adanya tuntutan perubahan serta adanya wewenang yang diberikan perusahaan bagi karyawan untuk mengubah ide, pemikiran menjadi suatu kreativitas sehingga dapat menghasilkan produk baru, proses baru ataupun teknologi baru yang akan meningkatkan kinerja keuangan perusahaan, produktivitas, serta pertumbuhan dan perbaikan dalam perusahaan.

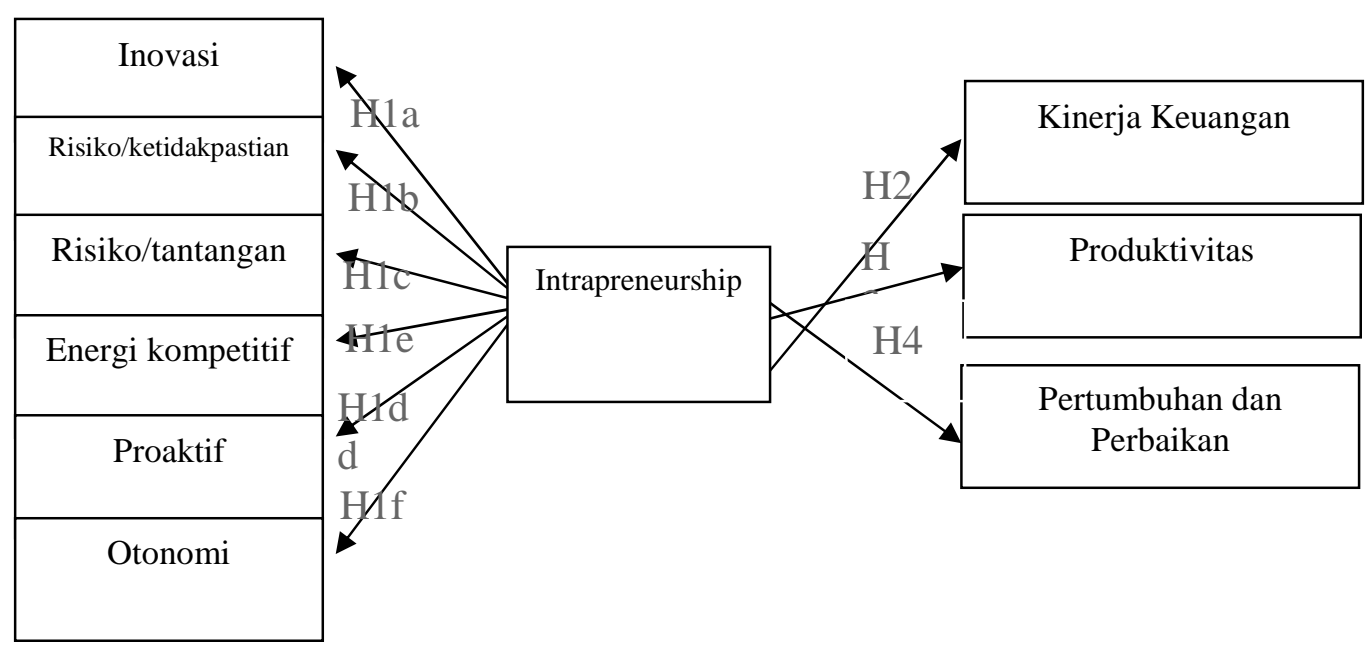

Gambar 1. Kerangka Pemikiran

Keterangan Hipotesis

H1: Intrapreneurship dapat dijelaskan oleh faktor inovasi, kecenderungan risiko dalam menghadapi ketidakpastian, risiko kecenderungan dalam menghadapi tantangan baru, energi yang kompetitif, proaktif dan otonomi.

Sehingga :

H1a: Inovasi mempunyai hubungan terhadap intrapreneurship.

H1b: Risiko/ketidakpastian mempunyai hubungan terhadap intrapreneurship.

H1c: Risiko/tantangan mempuyai hubugan terhadap intrapreneurship.

H1d: Energi kompetitif mempuyai hubugan terhadap intrapreneurship.

H1e: $\quad$ Proaktif mempuyai hubugan terhadap intrapreneurship.

H1f: $\quad$ Otonomi mempuyai hubugan terhadap intrapreneurship.

$\mathrm{H} 2$ : $\quad$ Intrapreneurship berpengaruh terhadap kinerja keuangan.

H3: Intrapreneurship berpengaruh terhadap produktivitas perusahaan.

H4: Intrapreneurship berpengaruh terhadap pertumbuhan dan perbaikan.

\section{METODE}

Populasi dalam penelitian ini adalah manager perusahan manufaktur yang ada di Provinsi Banten.Sampel yang digunakan dalam penelitian ini adalah middle management Strategic Business Unit (SBU) pada perusahaan manufaktur yang ada di Tangerang. 
Penelitian ini menggunakan data primer, dengan menyebarkan kuesioner secara langsung ke perusahaan. Dalam penelitian ini teknik pengambilan sampel yang digunakan adalah metode purposive sampling. Kriteria yang diajukan untuk sampel sebagai berikut:

a. Manajer perusahaan yang perusahaannya terdaftar di Dinas Perdagangan dan Perindustrian Provinsi Banten dan merupakan perusahaan menengah (sesuai dengan kriteria Undang-Undang No. 20 Tahun 2008 tentang UMKM).

b. Manajer produksi, manajer pemasaran, manajer keuangan, kepala divisi research and development, dan akuntan manajemen yang telah bekerja pada perusahaan selama lebih dari 2 tahun ( dengan harapan bagian-bagian tersebut lebih berpengalaman dan mengusai fungsi-fungsi pusat pertanggung jawaban dalam mengelola bagian-bagian yang menjadi tanggung jawabnya).

Dalam penelitian ini yang menjadi variabel independen adalah intrapreneurship $\left(\mathrm{X}_{1}\right)$. Variabel intrapreneurship memiliki enam faktor yaitu inovasi, risio/ketidakpastian, risiko/tantangan, energi kompetitif, proaktif dan otonomi serta variabel dependen yaitu kinerja keuangan $\left(\mathrm{Y}_{1}\right)$, produktivitas $\left(\mathrm{Y}_{2}\right)$, serta pertumbuhan dan perbaikan $\left(\mathrm{Y}_{3}\right)$.

Dalam penelitian ini, analisis data di sederhanakan dengan tahapan-tahapan sebagai berikut. Tahapan pertamamengindentifikasi data yang diperoleh dari lapangan,yang bersumber dari buku, literature, dan kuesioner. Tahapan kedua, yakni mengklasifikasikan data yang masuk, kemudian disesuaikan dengan permasalahan dan tujuan penelitian.Tahapan ketiga,yakni melakukan interpretatif terhadap faktor yang mempengaruhi.

Penelitian ini menggunakan pendekatan Structural Equation Modeling (SEM) dengan menggunakan path diagram yang memungkinkan untuk memasukkan semua variable unobserved sesuai dengan model teori yang ada. Menurut Ghozali (2008) Structural Equation Modeling (SEM) merupakan gabungan dari dua metode statistik yang terpisah yaitu analisis faktor (factor analysis) yang dikembangkan di ilmu psikologi dan psikometri dan model persamaan simultan (simultaneous equation modeling) yang dikembangkan di ekonometrika. Analisis data menggunakan SEM dengan program Analysis of Moment Structure (AMOS) 21.0.

\section{HASIL DAN PEMBAHASAN}

Dalam penelitian ini, kuesioner yang disebar sebanyak 200 eksemplar. Dari jumlah tersebut kuesioner yang kembali berjumlah 125 eksemplar atau 62,50\% responden yang mengembalikan. Kuesioner yang tidak kembali berjumlah 75 eksemplar kuesioner atau $37,50 \%$.

Setelah melakukan uji normalitas dan multikolinieritas, data dinyatakan berdistribusi normal. Selanjutnya dilakukan analisis faktor konfirmatori berdasarkan Persamaan Struktural Modelling (SEM) yang cocok untuk ini ukuran sampel. Pendekatan komprehensif dilakukan untuk menguji hipotesis tentang hubungan antara variabel yang diamati dan laten(Hoyle,1995). Penelitian ini menggunakan analisis struktur AMOS 21.0 untuk memperkirakan model pengukuran dan model strukturalkoefisien jalur dari hubungan antara variabel dalam model.

Analisis faktor konfirmatori yang pertama dilakukan pada konstruk eksogen. Diantara faktor yang membentuk intrapreneurship ada beberapa variabel yang memiliki nilai standardized loading estimate kurang dari0.40, sehingga harus di eleminasi dari analisis. Hasil dari modifikasi konstruk eksogen dapat dilihat pada gambar 2. 


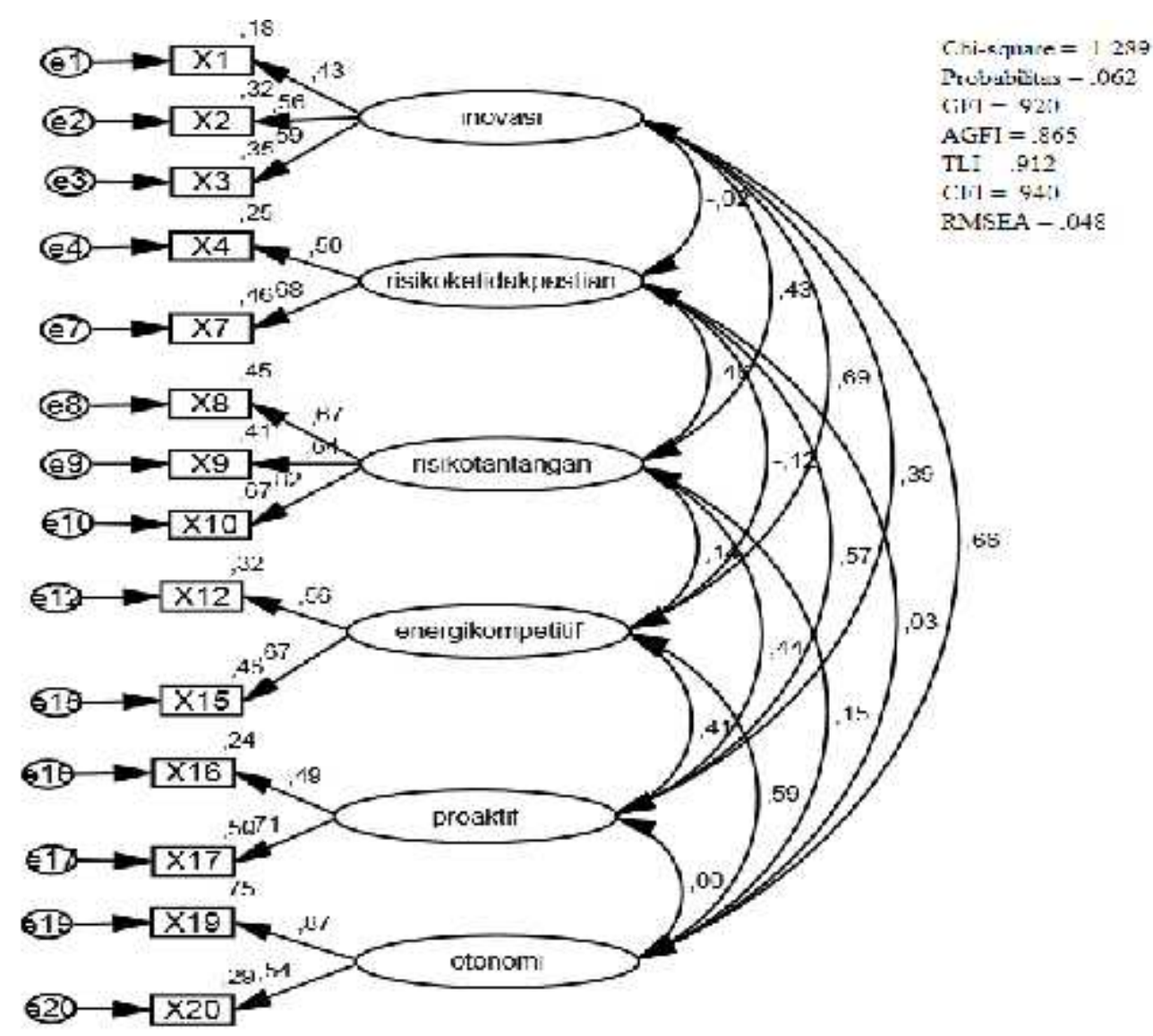

Gambar 2. Confirmatory factor analysis antar Konstruk Eksogen Sumber:Output AMOS 21, 2013

Tabel 1. Hasil Goodness of fit indicates

\begin{tabular}{|c|c|c|c|}
\hline $\begin{array}{l}\text { Goodness } \\
\text { ofFitIndex }\end{array}$ & Cut-of value & Hasil & Evaluasi \\
\hline Chi-square & Diharapkan kecil & 1.289 & \\
\hline Probabilitas & $\geq 0.05$ & 0.062 & FIT \\
\hline GFI & $\geq 0.90$ & 0.920 & FIT \\
\hline AGFI & $\geq 0.90$ & 0.865 & MARGINAL \\
\hline TLI & $\geq 0.90$ & 0.912 & FIT \\
\hline CFI & $\geq 0.90$ & 0.940 & FIT \\
\hline RMSEA & $\leq 0.08$ & 0.048 & FIT \\
\hline
\end{tabular}

Pada Tabel 1 dapat dilihat bahwa goodness of fit sudah menunjukkan model fit yang baik. Tingkat signifikansi chi-square pada 1,289 dengan probabilitas 0,062 menunjukkan bahwa hipotesis nol menyatakan tidak terdapat perbedaan antara matriks dan kovarian sampel dengan matriks dan kovarian populasi yang diestimasi tidak dapat ditolak. Dan GFI pada 0,920 menunjukkan tingkat penerimaan yang fit, begitu pula dengan kriteria fit lainnya yang menunjukkan nilai yang fit. 
Analisis faktor konfirmatori yang kedua dilakukan pada konstruk endogen. Diantara variabel-variabel laten yaitu kinerja keuangan, produktivitas, serta pertumbuhan dan perbaikan ada beberapa yang memiliki nilai standardized loading estimate kurang dari0.40, sehingga harus di eliminasi dari analisis. Hasil dari modifikasi konstruk endogen dapat dilihat pada gambar 4.2.

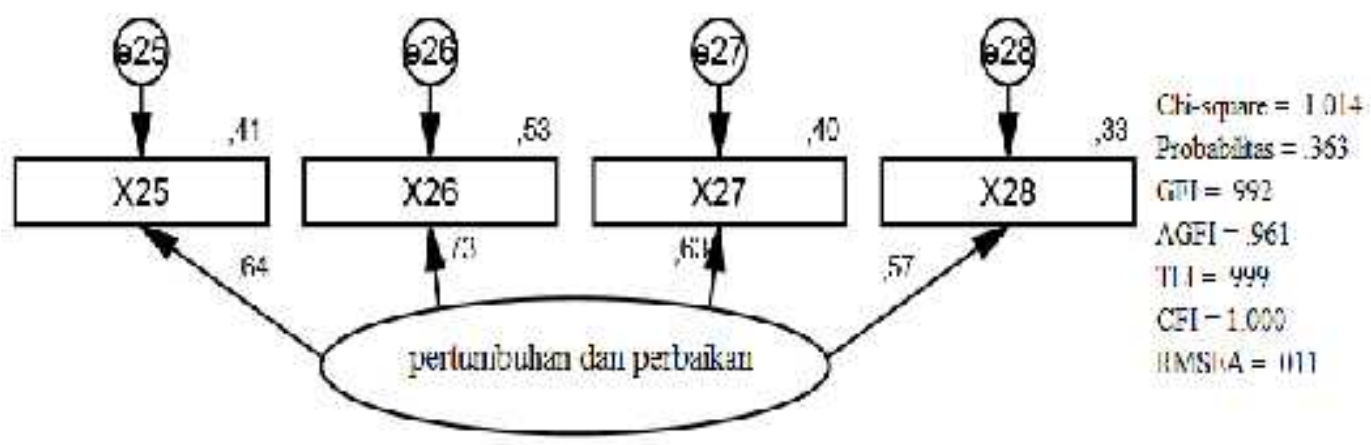

Gambar 3. Confirmatory Factor Analysis antar Konstruk Endogen Sumber:Output AMOS 21, 2013

Tabel 2. Hasil Goodness of fit Indicates

\begin{tabular}{lccc}
\hline \multicolumn{1}{c}{$\begin{array}{c}\text { Goodness of } \\
\text { Fit Index }\end{array}$} & Cut-of value & Hasil & Evaluasi \\
\hline Chi-square & Diharapkan kecil & 1.014 & \\
Probabilitas & $\geq 0.05$ & 0.363 & $F I T$ \\
GFI & $\geq 0.90$ & 0.992 & $F I T$ \\
AGFI & $\geq 0.90$ & 0.961 & $F I T$ \\
TLI & $\geq 0.90$ & 0.999 & FIT \\
CFI & $\geq 0.90$ & 1.000 & $F I T$ \\
RMSEA & $\leq 0.08$ & 0.011 & FIT \\
\hline
\end{tabular}

Dari Tabel di atas dapat dilihat bahwa goodness of fit sudah menunjukkan model fit yang baik. Tingkat signifikansi chi-square pada 1.521 dengan probabilitas pada 0.363 menunjukkan bahwa hipotesis nol menyatakan tidak terdapat perbedaan antara matriks dan kovarian sampel dengan matriks dan kovarian populasi yang diestimasi tidak dapat ditolak. Nilai GFI sebesar 0.992 menunjukkan tingkat penerimaan yang fit, begitu pula dengan kriteria fit lainnya yang menunjukkan nilai yang fit.

Setelah measurement model dianalisis melalui confirmatory factor analysis dan dilihat bahwa masing-masing indikator dapat mendefinisikan sebuah konstruk laten, maka langkah selanjutnya adalah melakukan analisis full model structural equation model. Dalam pengujian full model structural equation modeldilakukan dua macam pengujian yaitukesesuaian model serta uji signifikansikausalitas melalui pengujian koefisien regresi.Pengujian tersebut dengan memperhatikan proses analisis konfirmatori per 
konstruk, dengandemikian proses ini menguji model secara keseluruhan dengan model per konstruk yang telahdimodifikasi (modified model) sehingga terbentuk model yang baik. Analisis full modelstructural equationmodel.

Dilihat hasil goodness of fit indicates di dalam full model tidak ada yang memenuhi kriteria fit, maka penulis memutuskan untuk mengeliminasi dimensi otonomi dan risiko/ketidakpastian serta x25. Maka hasilnya akan tampak pada gambar 4.

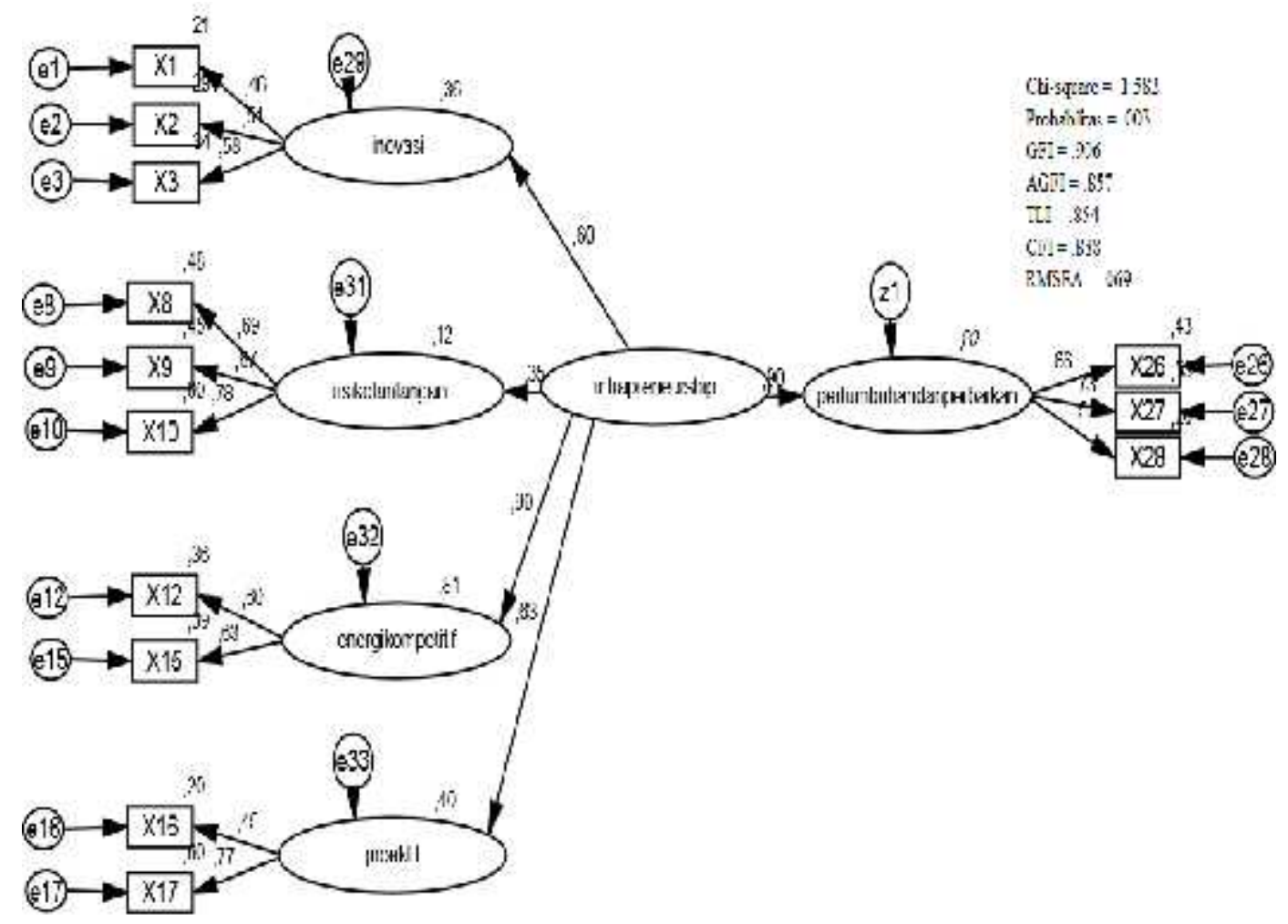

Gambar 4. Analisis Full Model Structural Equation

Sumber: Output AMOS 21, 2013

Ringkasan perbandingan model yang dibangun dengan cut off goodness of fit indicates yang ditetapkan, nampak pada tabel 3.

Tabel 3. Hasil Goodness of fit Model Struktural

\begin{tabular}{lllc}
\hline $\begin{array}{l}\text { Goodness of } \\
\text { Fit Index }\end{array}$ & Cut-of value & Hasil & Evaluasi \\
\hline Chi-square & Diharapkan kecil & 1.582 & \\
Probabilitas & $\geq 0.05$ & 0.003 & MARGINAL \\
GFI & $\geq 0.90$ & 0.906 & FIT \\
AGFI & $\geq 0.90$ & 0.857 & MARGINAL \\
TLI & $\geq 0.90$ & 0.854 & MARGINAL \\
CFI & $\geq 0.90$ & 0.888 & MARGINAL \\
RMSEA & $\leq 0.08$ & 0.069 & FIT \\
\hline
\end{tabular}


Uji Hipotesis 1 dan Pembahasan. Hipotesis yang pertama diuji untuk mengetahui kemampuan faktor inovasi, risiko kecenderungan dalam mengahadapi ketidakpastian, risiko kecenderungan dalam menghadapi tantangan, energi kompetitif, proaktif dan otonomi dalam menjelaskan intrapreneurship. Dari hasil olah data menggunakan program AMOS 21.0 diperoleh hasil sebagai berikut:

Tabel 4. Regression Weights: (Group number 1 - Default model)

\begin{tabular}{|c|c|c|c|c|c|c|}
\hline & & Estimate & S.E. & C.R. & $\mathrm{P}$ & Label \\
\hline Inovasi & $<---$ Intrapreneurship &, 156 & ,048 & 3,255 & ,001 & par_9 \\
\hline Risiko/ketidakpastia & <--- Intrapreneurship &,- 007 & 055 &,- 124 & 901 & \\
\hline Risiko/tantangan & $<---$ Intrapreneurship & 147 & 054 & 2,741 & ,006 & par_10 \\
\hline Energi kompetitif & $<---$ Intrapreneurship & ,226 & 042 & 5,366 & $* * *$ & par_11 \\
\hline Proaktif & $<---$ Intrapreneurship & 197 & 041 & 4,806 & $* * *$ & par_12 \\
\hline Otonomi & $<---$ Intrapreneurship &, 112 & 049 & 2,298 &, 022 & \\
\hline
\end{tabular}

H1a: nilai koefisien standardized 0.156 untuk dimensi inovasi, dengan nilai critical ratio (CR) 3.255, nilai $\mathrm{CR}$ tersebut berada diatas nilai kritis \pm 1.96 , dengan demikian H1a diterima.

H1b : nilai koefisien standardized -0.007 untuk dimensi risiko/ketidakpastian, dengan nilai critical ratio (CR) 0.901 , nilai CR tersebut berada diantara nilai kritis \pm 1.96 , dengan demikian H1b ditolak.

H1c: nilai koefisien standardized 0.147 untuk dimensi risiko/tantangan, dengan nilai critical ratio (CR) 2.741 nilai CR tersebut berada diatas nilai kritis \pm 1.96 , dengan demikian H1c diterima.

H1d : nilai koefisien standardized 0.226 untuk dimensi energi kompetitif, dengan nilai critical ratio (CR) 5.366, nilai CR tersebut berada diatas nilai kritis \pm 1.96 , dengan demikian H1d diterima.

H1e : nilai koefisien standardized 0.197 untuk dimensi proaktif, dengan nilai critical ratio(CR) 4.806, nilai $\mathrm{CR}$ tersebut berada diatas nilai kritis \pm 1.96 , dengan demikian H1e diterima.

H1f : nilai koefisien standardized 0.112 untuk dimensi otonomi, dengan nilai critical ratio(CR) 2,298, nilai CR tersebut berada diantara nilai kritis \pm 1.96 , namun karna model dibangun dengan cut off goodness of fit indicates untuk mendapatkan model yang baik, dengan demikian H1f ditolak.

Dari enam faktor yang mampu menjelaskan variabel intrapreneurship sebagian besar faktor mampu menjelaskan intrapreneurship secara baik yaitu faktor inovasi, risiko kecenderungan dalam menghadapi tantangan, energi kompetitif dan proaktif, sehingga hipotesis pertama (H1) diterima.

Hasil olah data pada Tabel 4 menunjukkan bahwa intrapreneurship mampu dijelaskan oleh inovasi, kecenderungan risiko dalam menghadapi ketidakpastian, risiko kecenderungan dalam menghadapi tantangan baru, energi kompetitif, proaktif dan otonomi. Hasil temuan ini sesuai dengan penelitian Felicio et al. (2012), namun terdapat faktor yang tidak konsisten dalam menjelaskan intrapreneurship dengan baik yaitu faktor risiko dalam menghadapi ketidakpastian dan otonomi. Hal tersebut didukung oleh Simon et al. (2000) dan Baron Ensley (2006) yang menemukan bahwa pengusaha memiliki persepsi yang 
lebih rendah terhadap risiko, sehingga lebih mampu menangkap peluang. Selain itu penelitian ini mengikuti temuan Knight (1997) yang secara empiris menemukan bahwa pengambilan risiko dan agresivitas kompetitif harus dimasukkan dalam dimensi yang sama dengan proaktif. Proaktif meliputi pengambilan inisiatif dan risiko dan agresivitas kompetitif dan keberanian yang tercermin dalam orientasi dan kegiatan manajemen puncak. Selain itu perbedaan hasil pada faktor otonomi dalam menjelaskan intrapreneurship menunjukkan bahwa pada perusahaan manufaktur di Tangerang dalam pemberian wewenang terhadap karyawan atau anggota organisasi belum diterapkan dengan baik, penerapan sistem operasi masih berdasarkan sistem operasional yang telah ada pada perusahaan.

Faktor-faktor yang membentuk intrapreneurship memiliki bobot yang berbeda dalam berbagai kepentingan, secara relatif, yang tentu saja akan memiliki efek yang berbeda dalam kaitannya dengan kinerja, observasi sejalan dengan penelitian oleh Lumpkin dan Dess (1996), Kreiseret al. (2002) dan Zahra dan Nielsen (2002), yang mengacu pada kenyataan bahwa faktor-faktor berbeda dalam dampaknya.

Uji Hipotesis 2 dan Pembahasan. Hipotesis yang kedua (H2) diuji untuk mengetahui pengaruh intrapreneurship terhadap kinerja keuangan. Dari hasil olah data menggunakan program AMOS 21.0 diperoleh hasil sebagai berikut:

Tabel 5. Regression Weights: (Group number 1 - Default model)

\begin{tabular}{lrrrrr}
\hline & Estimate & S.E. & C.R. & P & Label \\
\hline Kinerja keuangan <--- Intrapreneurship &, 174 &, 081 & 2,144 &, 032 & par_18 \\
\hline
\end{tabular}

Berdasarkan Tabel 5 dapat dilihat bahwa intrapreneurship mempengaruhi kinerja keuangan. Hal ini di tunjukkan dengan nilai koefisien standardized 0.174 , dengan nilai critical review (CR) 2.144, nilai CR tersebut berada diatas nilai kritis \pm 1.96 , namun berdasarkan measurement model dengan confirmatory analysis untuk konstruk endogen terdapat heywood case yaitu varian negatif sehingga variabel laten kinerja keuangan harus dihilangan. Dengan demikian hipotesis kedua (H2) ditolak.

Hasil olah data menunjukkan intrapreneurship tidak berpengaruh terhadap kinerja keuangan perusahaan. Hasil temuan ini konsisten dengan hasil penelitian Felicio et al. (2012) yang menyatakan intrapreneurship tidak berpengaruh terhadap kinerja keuangan.

Hal tersebut didukung oleh Wiklund dan Shepherd (2003) serta Zahra dan covin (1995). Dengan penerapan intrapreneurship yang baik dalam perusahaan memiliki efek kinerja yang cenderung sederhana dalam selama beberapa tahun pertama, dan dapat meningkat dari waktu ke waktu, hal tersebut menunjukkan bahwa intrapreneurship yang diterapkan dengan baik dalam perusahaan umumnya efektif untuk meningkatkan kinerja keuangan perusahaan dalam jangka panjang.

Uji Hipotesis 3 dan Pembahasan. Hipotesis yang ketiga (H3) diuji untuk mengetahui pengaruh intrapreneurship terhadap produktivitas perusahaan. Dari hasil olah data menggunakan program AMOS 21.0 diperoleh hasil sebagai berikut: 
Tabel 6. Regression Weights: (Group number 1 - Default model)

$\begin{array}{lccccc} & \text { Estimate } & \text { S.E. } & \text { C.R. } & \text { P } & \text { Label } \\ \text { Produktivitas <--- Intrapreneurship } & -, 148 & , 288 & -, 513 & , 608 & \text { par_19 }\end{array}$

Berdasarkan Tabel 6 dapat dilihat bahwa intrapreneurship tidak mempengaruhi produktivitas perusahaan. Hal ini di tunjukkan dengan nilai koefisien standardized -0.148 , dengan nilai critical review $(\mathrm{CR})-0.513$. nilai $\mathrm{CR}$ tersebut berada diantara nilai kritis \pm 1.96 , dengan demikian hipotesis tiga (H3) ditolak. Selain itu berdasarkan measurement model dengan confirmatory analysis untuk konstruk endogen terdapat heywood case yaitu varian negatif sehingga variabel laten produktivitas harus dihilangan. Dengan demikian hipotesis ketiga ditolak.

Hasil olah data menunjukkan intrapreneurship tidak berpengaruh terhadap produktivitas perusahaan. Hasil temuan ini konsisten dengan hasil penelitian Felicio et al. (2012) yang menyatakan intrapreneurship tidak berpengaruh terhadap produktivitas perusahaan. Penerapan Intrapreneurship pada perusahaan akan memudahkan pelaksanaan inovasi yang dimiliki oleh karyawan, tentunya dalam penerapan inovasi guna kemandirian perusahaan, perusahaan akan mencoba pasar terlebih dahulu, sehingga dampaknya belum dapat dirasakan secara signifikan bagi produktivitas perusahaan.

Uji Hipotesis 4 dan Pembahasan. Hipotesis yang keempat (H4) diuji untuk mengetahui pengaruh intrapreneurship terhadap pertumbuhan dan perbaikan perusahaan. Dari hasil olah data menggunakan program AMOS 21.0 diperoleh hasil sebagai berikut:

Tabel 7. Regression Weights: (Group number 1 - Default model)

\begin{tabular}{lcccccc}
\hline & Estimate & S.E. & C.R. & P & Label \\
\hline Pertumbuhan dan perbaikan <--- intrapreneurship &, 489 &, 079 & 6,216 & $* * *$ & par_21 \\
\hline
\end{tabular}

Berdasarkan Tabel 7 dapat dilihat bahwa intrapreneurship mempengaruhi pertumbuhan dan perbaikan perusahaan. Hal ini di tunjukkan dengan nilai koefisien standardized 0.489 , dengan nilai critical review (CR) 6.216 , nilai CR tersebut berada diatas nilai kritis \pm 1.96 , dengan demikian hipotesis keempat (H4) diterima.

Hasil olah data pada tabel 4.7 menunjukkan intrapreneurship berpengaruh positif signifikan terhadap pertumbuhan dan perbaikan. Hasil temuan ini konsisten dengan hasil penelitian Felicio et al. (2012) yang menyatakan intrapreneurship berpengaruh positif terhadap perbaikan dan pertumbuhan perusahaan.

Intrapreneurship sebagai instrumen dasar untuk konversi, akumulasi dan memanfaatkan sumber daya untuk tujuan kompetitif. Hasilnya adalah fokus pada pengembangan dan pemanfaatan produk, inovasi administrasi dan peremajaan serta redefinisi perusahaan untuk mendukung strategi bisnis mereka dan memastikan pengembangan perusahan dalam pertumbuhan dan perbaikan.

\section{PENUTUP}

Simpulan. (1) Intrapreneurship dapat dijelaskan oleh faktor inovasi, risiko kecenderungan dalam menghadapi tantangan baru, energi kompetitif, proaktif, namun tidak dapat dijelaskan oleh faktor kecenderungan risiko dalam menghadapi ketidakpastian dan 
otonomi. Hal tersebut didukung oleh Simon et al. (2000) dan Baron Ensley (2006) yang menemukan bahwa pengusaha memiliki persepsi yang lebih rendah terhadap risiko, sehingga lebih mampu menangkap peluang. (2) Intrapreneurship tidak berpengaruh terhadap kinerja keuangan perusahaan. Hal tersebut didukung oleh penelitian Felicio et al. (2012), Wiklund dan Shepherd (2003) serta Zahra dan covin (1995). Dengan penerapan intrapreneurship dengan baik dalam perusahaan memiliki efek kinerja yang cenderung sederhana dalam selama beberapa tahun pertama, dan dapat meningkat dari waktu ke waktu, hal tersebut menunjukkan bahwa intrapreneurship yang diterapkan dengan baik dalam perusahaan umumnya efektif untuk meningkatkan kinerja keuangan perusahaan dalam jangka panjang. (3) Intrapreneurship tidak berpengaruh terhadap produktivitas perusahaan. Hal tersebut didukung oleh penelitian Felicio et al. (2012). (4) Intrapreneurship berpengaruh terhadap pertumbuhan dan perbaikan. Hasil temuan ini konsisten dengan hasil penelitian Felicio et al. (2012) yang menyatakan intrapreneurship berpengaruh positif terhadap perbaikan dan pertumbuhan perusahaan. Intrapreneurship sebagai instrumen dasar untuk konversi, akumulasi dan memanfaatkan sumber daya untuk tujuan kompetitif. Hasilnya adalah fokus pada pengembangan dan pemanfaatan produk, inovasi administrasi dan peremajaan serta redefinisi perusahaan untuk mendukung strategi bisnis mereka dan memastikan pengembangan perusahan dalam pertumbuhan dan perbaikan. (5) Penelitian ini menegaskan bahwa faktor-faktor yang membentuk intrapreneurship memiliki bobot yang berbeda dalam berbagai kepentingan, secara relatif, yang tentu saja akan memiliki efek yang berbeda dalam kaitannya dengan kinerja, observasi sejalan dengan penelitian oleh Lumpkin dan Dess (1996), Kreiser et al. (2002) dan Zahra dan Nielsen (2002), yang mengacu pada kenyataan bahwa faktor-faktor berbeda terhadap dampaknya.

Saran. (1) Intrapreneurship sebagai instrumen dasar untuk konversi, akumulasi dan memanfaatkan sumber daya untuk tujuan kompetitif. Hasilnya adalah fokus pada pengembangan dan pemanfaatan produk, inovasi administrasi dan peremajaan serta redefinisi perusahaan untuk mendukung strategi bisnis mereka dan memastikan pengembangan perusahan dalam pertumbuhan dan perbaikan, maka diharapkan perusahaan dapat menerapkan intrapreneurship dengan baik guna mecapai kinerja perusahaan yang baik. (2) Penelitian selanjutnya dapat menguji faktor-faktor pembentuk intrapreneurship terlebih dahulu guna mendapatkan faktor-faktor yang tepat untuk menjelaskan intrapreneurship dengan baik, karena intrapreneurship memiliki banyak faktor-faktor pembentuk yang berbeda dan akan menghasilkan dampak yang berbeda pula. (3) Penelitian selanjutnya dapat dilakukan dengan mengembangkan instrumen penelitian, yaitu penambahan variabel penelitian kinerja non-keuangan.(4) Penelitian berikutnya dapat dilakukan dengan menambah jumlah sampel perusahaan yang cakupannya lebih luas yaitu seluruh perusahaan yang ada di Provinsi Banten, karena populasi yang diambil dalam penelitian ini hanya perusahaan yang berada di wilayah Tangerang. (5) Penelitian selanjutnya dapat dilakukan dengan jangka waktu pengamatan yang lebih panjang, sehingga dapat diketahui pengaruhnya terhadap kinerja keuangan dan produktivitas perusahaan. (6) Penelitian selanjutnya dapat dilakukan pada perusahaan kecil maupun perusahaan besar serta pada perusahaan sektor lainnya agar dapat membandingkan dampak intrapreneurship yang terjadi terhadap kinerja perusahaan. 


\section{DAFTAR RUJUKAN}

Alpkan, L., Bulut, C., Gunday, G., Ulusoy, G. and Kilic, K., (2010) "Organizational support for intrapreneurship and its interaction with human capital to enhance innovative performance", Management Decision, Vol. 48 (5) pp. 732-55.

Antoncic, B. and Hisrich, R.D., (2001) "Intrapreneurship: construct refinement and crosscultural validation", Journal of Business Venturing, Vol. 16 (5) pp. 495-527.

Antoncic, B. and Hisrich, R.D., (2004) "Corporate entrepreneurship contingencies andorganizational wealth creation", Journal of Management Development, Vol. 23 (6) pp. 518-50.

Bosma, N. and Levie, J. (2010) Global Entrepreneurship Monitor: 2009 Global Report, Global Entrepreneurship Research Association, Boston, MA.

Covin, J.G. and Slevin, D.P. (1991) "A conceptual model of entrepreneurship as firm behaviour", Entrepreneurship Theory and Practice, Vol. 16 (1) pp. 7-25.

Covin, J.G. and Miles, M.P. (1999) "Corporate entrepreneurship and the pursuit of competitiveadvantage", Entrepreneurship: Theory \& Practice, Vol. 23 (3) pp. 47-63.

Covin, J.G., \& Slevin, D.P. (1986) The development and testing of an organizational-level entrepreneurship scale. In R. Ronstadt, et al. (Eds.), Frontiers of Entrepreneurship Research.Wellesley, MA: Babson College.

Djajendra. (2013) [ONLINE] http://www.coachgetty.com/articleDetail/173/12-karakterintrapreneur.html.

Dess, G.G., Ireland, R.D., Zahra, S.A., Floyd, S.W., Janney, J.J. dan Lane, P.J. (2003) "Emerging issues in corporate entrepreneurship", Journal of Management, Vol. 29 (3) pp. 351-78.

Felicio J.A., Ricardo R., and V1'tor R. C. (2012) "The effect of intrapreneurship on corporate performance, Management Decision Journal. Vol 50 (10) pp. 1717-1738.

Kanter, R.M., and Richardson, L. (1991) "Engines of progress: Designing and running entrepreneurial vehicles in established companies-The Enter-prize program at Ohio Bell, 1985-1990", Journal of Business Venturing 6 (3) pp. 209-229.

Lumpkin, G. and Dess, G. (1996) "Clarifying the entrepreneurial orientation construct and linking it to performance", Academy of Management Review, Vol. 21 (1), pp. 135-72.

Miller, D. (1983) "The correlates of entrepreneurship in three types of firms", Management Science, Vol. 29, pp. 770-91.

Pinchot III, Gifford. (1985) Intrapreneuring: Why you don't have to leave the corporation to became an Entrepreneur. Harper \& Row. New York.

Rule, E.G., and Irwin D.W. (1988) "Fostering intrapreneurship: The new competitive edge",The Journal of Business Strategy 9 (3) pp. 44-47.

Soriano, D.R. and Martinez, J.M. (2007) "Transmitting the entrepreneurial spirit to the work team in SMEs: the importance of leadership", Management Decision, Vol. 45 (7) pp. 1102-22.

Srimindarti, Ceacilia. (2004) "Balanced scorecard sebagai alternative pengukuran kinerja". Fakultas ekonomi, Vol. 3 (1) April, hal 52-64.

Wirawan, (2012) [ONLINE] http://entrepreneurisme.com/entrepreneur-vs-intrapreneurmanakah-yang-anda-pilih/.

Zahra, A. (1991) "Predictors and financial outcomes of corporate entrepreneurship: an exploratory study", Journal of Business Venturing, Vol. 6 (4) pp. 259-86. 